Frontiers of Information Technology \& Electronic Engineering www.jzus.zju.edu.cn; engineering.cae.cn; www.springerlink.com ISSN 2095-9184 (print); ISSN 2095-9230 (online)

E-mail: jzus@zju.edu.cn

\title{
Erratum:
}

\section{Erratum to: Efficient keyword search over graph-structured data based on minimal covered $r$-cliques}

\author{
Asieh GHANBARPOUR ${ }^{1,2}$, Abbas NIKNAFS ${ }^{1}$, Hassan NADERI ${ }^{\dagger+1}$ \\ ${ }^{1}$ School of Computer Engineering, Iran University of Science and Technology, Tehran 13114-16846, Iran \\ ${ }^{2}$ Department of Computer Engineering, University of Sistan and Baluchestan, Zahedan 98167-45845, Iran \\ †E-mail: naderi@iust.ac.ir
}

https://doi.org/10.1631/FITEE.18e0133

Erratum to: Front Inform Technol Electron Eng, 2020, 21(3):448-464

https://doi.org/10.1631/FITEE.1800133

Unfortunately the second author's name has

been misspelt. It should be read: Abbas NIKNAFS.

The online version of the original article can be found at https://doi.org/10.1631/FITEE.1800133

\footnotetext{
Corresponding author

(D) ORCID: Hassan NADERI, https://orcid.org/0000-0002-3296-8505

(C) Zhejiang University and Springer-Verlag GmbH Germany, part of Springer Nature 2020
} 